\title{
Common First-Year Engineering Curriculum in British Columbia
}

\author{
Brian Dick, Vancouver Island University ${ }^{\prime}$; Yang Cao, University of British Columbia; Jennifer \\ Kirkey, Douglas College; Margaret Gwyn, University of Victoria; Barbara Rudecki, College of \\ New Caledonia; Elroy Switlishoff, Selkirk College; Tara Todoruk, Columbia College
}

\begin{abstract}
Labour market demand for engineers continues to outpace the capacity of postsecondary institutions to produce new entrants to the field. Providing for the diverse pathways students may take for their education could both increase the numbers of potential candidates, as well as improve the likelihood of those candidates successfully completing engineering programs. The British Columbia Council on Admission and Transfer (BCCAT) Engineering Articulation committee leveraged overlap within the content and delivery requirements of first-year engineering programs at most engineering schools in the province and developed a sector-wide common first-year engineering curriculum.
\end{abstract}

This common first-year engineering curriculum delivers a core natural science and math content (e.g. calculus, physics), and introduces students early to concepts in engineering design, sustainability, engineering practice and social responsibility, safety, and ethics. Students are also expected to complete client-based project work comprising of integrated, multi-disciplinary sub-systems.
This first-year curriculum ensures that instructors for first-year engineering design and science course are professionally designated (P.Eng or Eng.L), and delivers a minimum accreditation unit (AU) content with specified graduate attributes at an introductory level.

Institutions comprising of over $90 \%$ of the seat capacity within engineering education in British Columbia have agreed in principal that this curriculum fulfills their first-year requirements and provides a pathway for entry into the 2 ndyear of engineering studies at their respective institutions. The alignment of core and firstyear competency requirements is anticipated to improve the efficiency of the overall transfer process between institutions, and expand general student capacity and interest in the field. Future work includes assisting smaller institutions to build capacity and align to the content and delivery needs of the common firstyear curriculum.

\footnotetext{
${ }^{1}$ Corresponding Author: brian.dick@viu.ca
} 